\title{
Isolated Tuberculosis of Talonavicular Joint of Foot
}

\author{
${ }^{1}$ Deepinderjit Singh, ${ }^{2}$ Amit Lakhani, ${ }^{3}$ Gagandeep Kaur
}

\begin{abstract}
Tuberculosis of foot is a rare entity, accounting for only $10 \%$ of osteoarticular tuberculosis. Its ability to mimic other common disorders can lead to delay in the diagnosis and proper treatment, particularly when it occurs in isolation. Here, we present a rare case of isolated tuberculosis of talonavicular joint of foot in an otherwise healthy male of 26 years.
\end{abstract}

Keywords: Isolated tuberculosis, Osteoarticular tuberculosis, Talonavicular joint.

How to cite this article: Singh D, Lakhani A, Kaur G. Isolated Tuberculosis of Talonavicular Joint of Foot. J Foot Ankle Surg (Asia-Pacific) 2015;2(2):94-96.

Source of support: Nil

Conflict of interest: None

\section{INTRODUCTION}

Musculoskeletal tuberculosis accounts for around less than $3 \%$ of all tuberculosis, while foot involvement accounts for less than $10 \%$ of osteoarticular tuberculosis. ${ }^{1,2}$ Tarsal bones are infrequently affected. ${ }^{3}$ Isolated tubercular lesion of one joint or one tarsal or metatarsal bone of foot is exception. ${ }^{4}$ Being less common and its tendency to mimic common disorders, like rheumatoid arthritis, osteoarthritis, tuberculosis of foot is commonly misdiagnosed and is detected at an advanced stage. ${ }^{5}$

\section{CASE REPORT}

We present a case of 26-year-old laborer (resident of Kashmir) who came to our outpatient clinic in December 2012 with a history of right foot pain that started 4 months ago. Pain was continuous and increased on bearing weight on the foot (i.e. on walking or standing). There was no history of trauma, fever, weight loss or loss of appetite. No history of previous treatment for tuberculosis. He had been under treatment with antibiotics and nonsteroidal anti-inflammatory drugs (NSAIDs) before

\footnotetext{
${ }^{1-3}$ Assistant Professor

1,2Department of Orthopedics, Maharishi Markandeshwar Medical College and Hospital, Solan, Himachal Pradesh, India

${ }^{3}$ Department of Microbiology, Maharishi Markandeshwar Medical College and Hospital, Solan, Himachal Pradesh, India

Corresponding Author: Deepinderjit Singh, Assistant Professor Department of Orthopedics, Maharishi Markandeshwar Medical College and Hospital, Solan, Himachal Pradesh, India, Phone: 9872274656, e-mail: drdeepinder82@gmail.com
}

he visited us. On physical examination, right foot had swelling on dorsum (Fig. 1) with wasting of right leg (Fig. 2). There was no redness, dilated veins, local rise of temperature and lymphadenopathy. Eversion and inversion movements were restricted and painful while dorsiflexion and plantar flexion were terminally painful but full range of movement was there. Laboratory findings demonstrated an erythrocyte sedimentation rate (ESR) of $20 \mathrm{~mm}$ during the first hour with normal complete blood counts (CBC) profile. Preoperative X-ray (Fig. 3) of the right foot showed gross talonavicular joint destruction with erosion of the navicular bone. Preoperative computed tomography (CT) scan (Fig. 4) was done, showing extensive navicular destruction with destruction of head of talus. A chest X-ray was normal and Monteux skin testing was negative. In light of raised

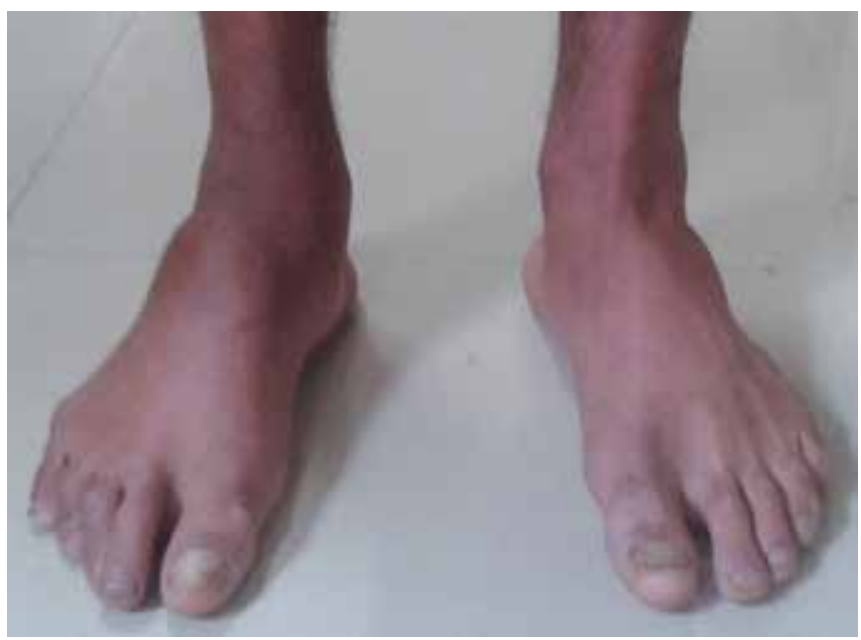

Fig. 1: Swelling dorsum of foot

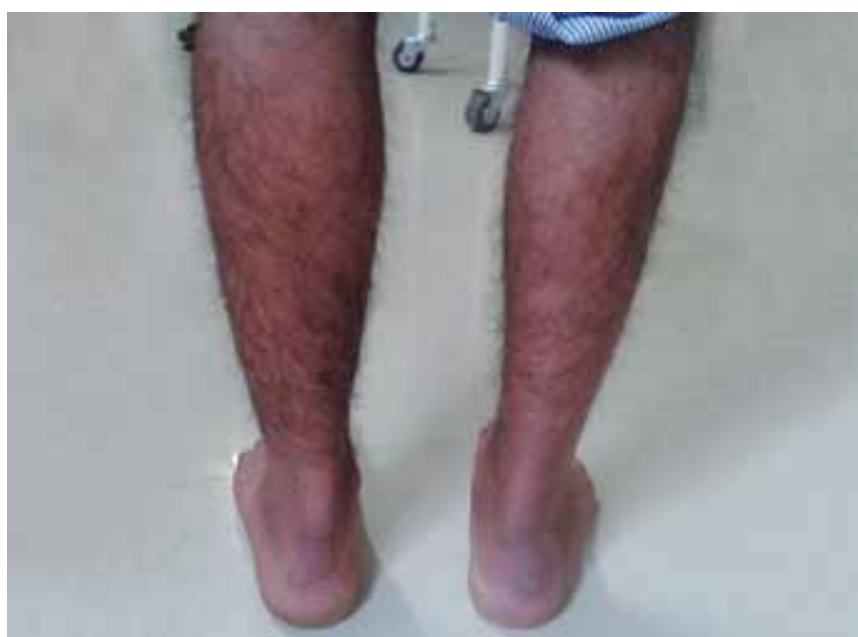

Fig. 2: Wasting of right leg 


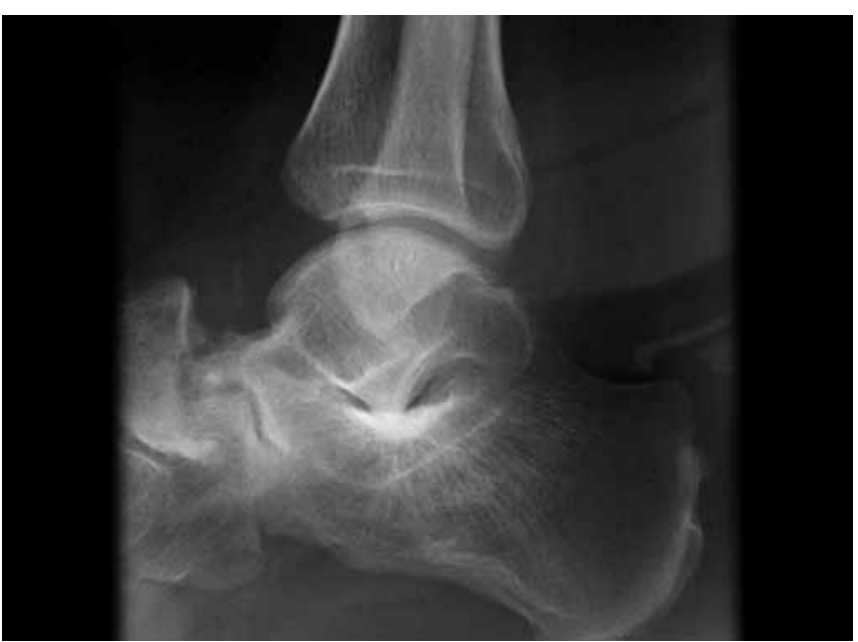

Fig. 3: Preoperative X-ray

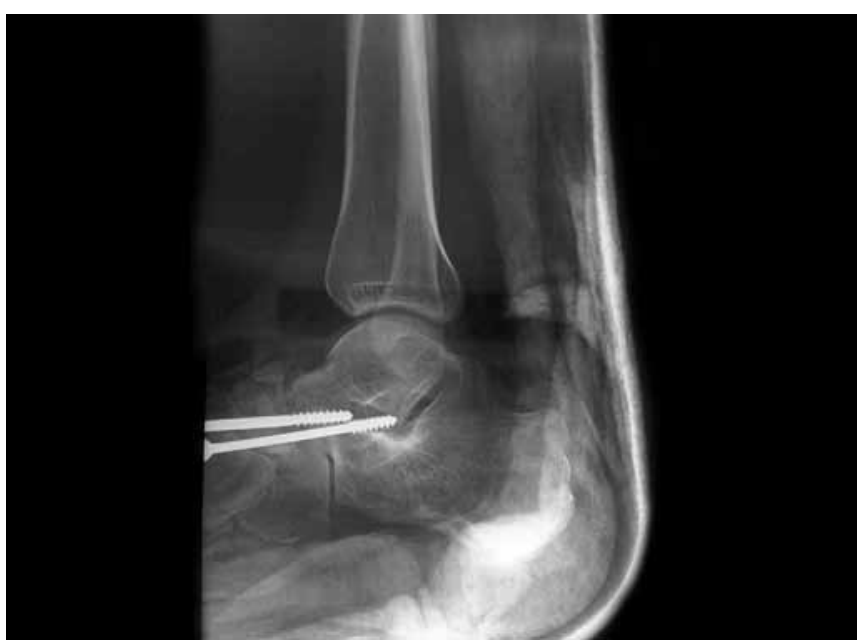

Fig. 5: Postoperative X-ray

ESR and radiological findings, the patient was taken up for surgery as a diagnostic (biopsy of the lesion) as well as a therapeutic procedure in the form of talonavicular arthodesis. Intraoperatively, crumbly grayish soft tissue around the talonavicular joint was seen which was entirely removed by curettage. Talonavicular arthrodesis was done using two partially threaded cancellous screws alongwith bone graft taken from ipsilateral proximal tibia, as seen in postoperative X-ray (Fig. 5). Below knee plaster splint was given for 4 weeks. Anti-tubercular treatment (four drugs regimen) was started soon after the diagnosis was confirmed on histopathological findings. Afterwards, a below knee POP cast was given allowing partial-weightbearing for one month followed by full weightbearing in the POP cast for another month. The screws were removed at a hospital (near place of residence of the patient) at 4 months, after radiological confirmation of talonavicular arthrodesis. The patient received a total 9 months of antituberculosis chemotherapy. At the end of 9 months follow-up (Fig. 6), patient was pain-free and having full-weightbearing on the involved foot.

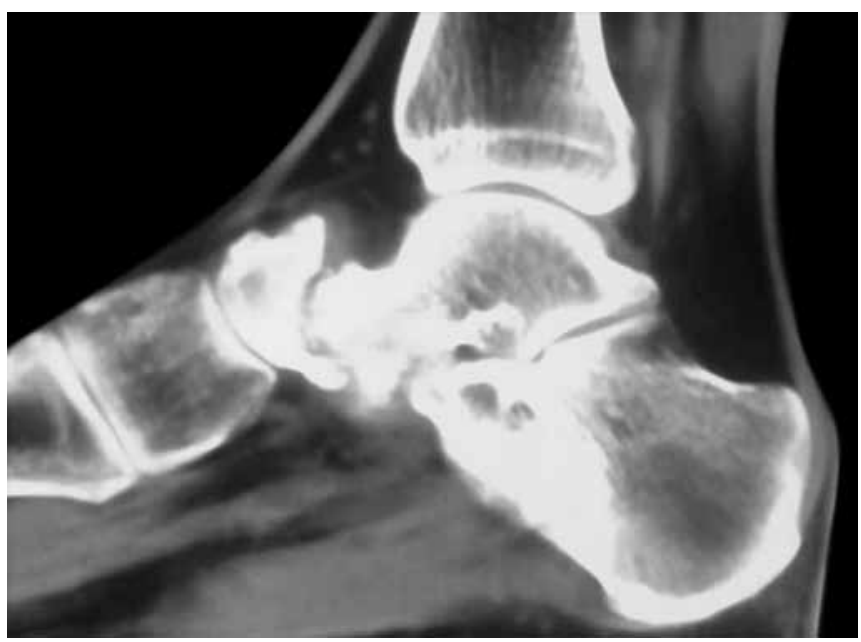

Fig. 4: Preoperative CT scan

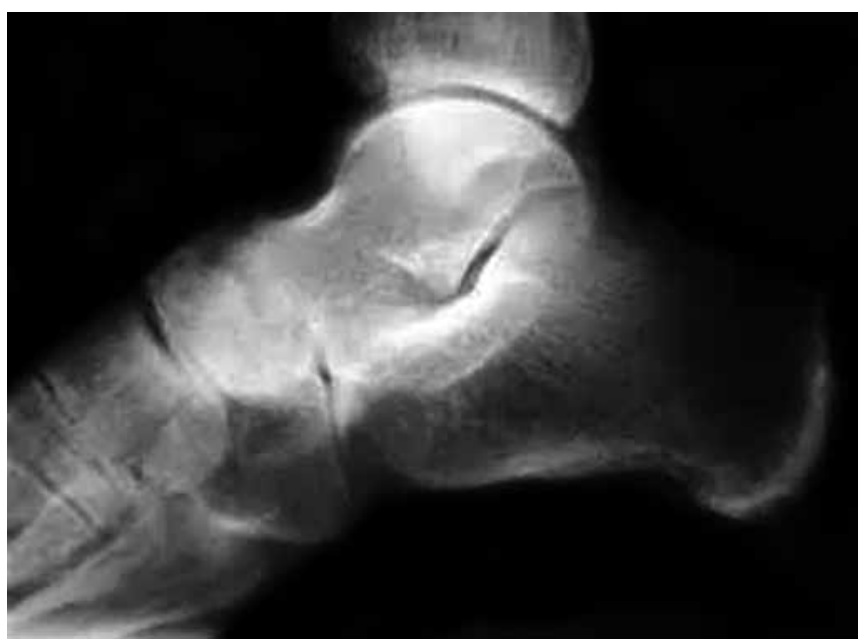

Fig. 6: Nine months follow-up

\section{DISCUSSION}

In the field musculoskeletal tuberculosis, spinal tuberculosis and major joint tuberculosis (hip and knee) are common. ${ }^{6}$ Osteoarticular tuberculosis of foot, by contrast, is less common. The bones involved are usually the calcaneum, talus, first metatarsal, navicular and medial and intermediate cuneiforms. ${ }^{4}$

The presenting symptoms are those of any other musculoskeletal disorder: pain, stiffness and swelling.? But there is, characteristically, early muscle atrophy, as is seen in our case. ${ }^{7}$

Skeletal tuberculosis is a paucibacillary entity, in comparison to pulmonary lesions, as a result it is very difficult to isolate and demonstrate the organism. Dhillon et al reported positive cultures of acid fast bacilli (AFB) in only four out of 66 cases of osteoarticular tuberculosis of the foot. ${ }^{8}$

Imaging plays a major role in diagnosing the problem. Radiologically, the characteristic feature of TB arthritis is called 'Phemister's triad'. This feature is characterized by juxta-articular osteoporosis, peripherally located osseous 
erosions and gradual narrowing of the joint space. ${ }^{9}$ This is in contrast to rheumatoid arthritis and pyogenic arthritis, in which joint space narrowing occurs early in the course of the disease. ${ }^{10}$ Rastogi et al described five patterns of tubercular lesions seen in foot on X-rays: cystic, rheumatoid, subperiosteal, kissing and spina ventosa. ${ }^{11}$ In our case, the lesion was kissing type where infection was localized to one joint and symmetrical scalloped lesions had developed on the adjacent articular surfaces of the bones. Computed tomography scan and magnetic resonance imaging (MRI) have the advantage of delineating intramedullary lesions earlier then radiography, thus can help diagnosing the disease earlier alongwith other parameters taken into account. In endemic regions, the clinical features, radiological appearance and elevated ESR are sufficient to diagnose tuberculosis and begin treatment. ${ }^{10}$ Although biopsy is indicated only in doubtful cases, which was done in our case. The surgery was done as a therapeutic procedure as well, in the form of talonavicular arthrodesis using two partially threaded screws.

To our knowledge in the literature, there are less than 10 cases of isolated tuberculous osteomyelitis of the talus ${ }^{12}$ and only two reports of talonavicular tuberculosis both in adults, and one with multifocal involvement, ${ }^{13,14}$ thus, our case is an extremely rare case of isolated talonavicular tuberculosis in adults. The long period before definite diagnosis of our patient may be justified by the fact that he was systemically well and afebrile. Although the osteopenia and destructive pattern on imaging is typical, it is not diagnostic.

Our case report demonstrates that tuberculosis can affect rare sites, making diagnosis difficult. As ours is an endemic country, we recommend high degree of suspicion in conditions where symptoms are not resolving with routine treatment and thorough investigation to clinch the diagnosis.

\section{REFERENCES}

1. Rasool MN. Osseous manifestations of tuberculosis in children. J Ped Ortho 2001;21(6):749-755.

2. Dhillon MS, Sharma S, Gill SS, Nagi ON. Tuberculosis of bones and joints of the foot: an analysis of 22 cases. Foot Ankle 1993;14(9):505-513.

3. Dalldorf PG, Banas MP, Marquardt JD. Tuberculosis of the foot: a case report. Foot Ankle International 1994;15(3): 157-161.

4. Tuli SM. Tuberculosis of the skeletal system (bones, joints, spine and bursal sheaths). 4th ed. New Delhi: Jaypee Brothers Medical Publishers (P) Ltd; 2010;132-138.

5. Shetty MS, Kumar MA, Prabhu J. Tuberculosis of midtarsal joints: a diagnostic dilemma. JIMSA 2011;24(1):39.

6. Evanchick CC, Davis DE, Harrington TM. Tuberculosis of peripheral joints: an often missed diagnosis. J Rheumatol 1986;13(1):187-189.

7. Messner RP. Arthritis due to mycobacteria, fungi and parasites. In: McCarty DJ, Koopman WJ. Arthritis and allied conditions: textbook of rheumatology. Philadelphia: Lea and Febiger; 1993;2:2035-2046.

8. Dhillon MS, Singh P, Sharma S, Gill SS, Nagi ON. Tuberculous osteomyelitis of the cuboid: a report of four cases. J Foot Ankle Surg 2000;39(5):329-335.

9. Sobel E, Levitz S. Tuberculosis of the foot: a diagnostic challenge. J Am Pediatr Med Assoc 1995;85(2):83-90.

10. Griffith JF, Kumta SM, Leung PC, Cheng JC, Chow LT, Metreweli C. Imaging of musculoskeletal tuberculosis: a new look at an old disease. Clin Ortho Rel Res 2002 May;398: 32-39.

11. Mittal R, Gupta V, Rastogi S. Tuberculosis of foot. J Bone Joint Surg (Br) 1999;81(6):997-1000.

12. Ebrahimzadeh $\mathrm{MH}$, Fattahi A. Isolated tuberculosis of talus, an extremely rare occurrence. Foot 2005;15(1): 59-61.

13. Foster PAL, Bismil Q, Venkateswaran B, Shanker J. Delayed presentation of tuberculosis of the talonavicular joint: a case report. J Foot Ankle Surg 2003;9(4):237-239.

14. Vaughan KD. Extraspinal osteoarticular tuberculosis a forgotten entity. West Ind Med J 2005;54(3):202-206. 